\title{
Distribuição Espacial e Cobertura de Vegetação das Tipologias de Áreas Verdes de Curitiba, PR
}

\author{
Mayssa Mascarenhas Grise ${ }^{1}$, Daniela Biondi ${ }^{2}$, Hideo Araki ${ }^{3}$
}

${ }^{1}$ Programa de Pós-graduação em Engenharia Florestal, Universidade Federal do Paraná - UFPR, Curitiba/PR, Brasil ${ }^{2}$ Departamento de Engenharia Florestal, Universidade Federal do Paraná - UFPR, Curitiba/PR, Brasil

${ }^{3}$ Departamento de Geomática, Universidade Federal do Paraná - UFPR, Curitiba/PR, Brasil

\begin{abstract}
RESUMO
A vegetação nas cidades desempenha funções ecológicas, estéticas e sociais que melhoram a qualidade de vida urbana. Para que essas funções sejam eficientes é necessário a realização de estudos quantitativos e qualitativos das áreas verdes (AVs) na cidade. O objetivo do estudo foi identificar a cobertura de vegetação presente nas diferentes tipologias de AVs nas unidades administrativas de Curitiba, PR, bem como analisar sua configuração espacial ao longo da paisagem urbana. A cobertura de vegetação foi identificada por meio da classificação por árvore de decisão de imagens de satélite de alta resolução espacial - GeoEye-1. Conclui-se que Curitiba possui menos de $5 \%$ de sua área constituída por AVs, as quais, em sua maioria, apresentaram cobertura de vegetação acima de $70 \%$. A distribuição espacial delas é desigual em quantidade e irregular quanto à sua disposição. A unidade administrativa da região Sul carece de AVs de todas as tipologias estabelecidas pela municipalidade.
\end{abstract}

Palavras-chave: paisagem; praça; parque.

\section{Spatial Distribution and Vegetation Cover of Green Areas in Curitiba, Parana state, Brazil}

\begin{abstract}
Vegetation in cities presents ecological, aesthetic and social functions that improve urban quality of life. However, quantitative and qualitative studies on the spatial distribution of green areas (GA) are needed to promote their efficiency. The aim of this study was to identify the vegetation cover present in different types of GAs in Curitiba, Parana state, and analyze the spatial configuration along the urban landscape. The vegetation cover was identified by means of the Decision Tree classification of high spatial resolution satellite images - GeoEye-1. The results show that Curitiba has less than $5 \%$ of its area composed of GAs, with most of them presenting vegetation coverage above $70 \%$. The distribution of these GAs is uneven in quantity and irregular in disposal.
\end{abstract}

Keywords: landscape; square; park. 


\section{INTRODUÇÃO}

O aumento da população mundial vivendo em áreas urbanas tem despertado preocupação acerca da qualidade de vida nessas áreas. As paisagens urbanas estão sofrendo cada vez mais as consequências do aumento da pressão sobre os recursos naturais, do crescimento desordenado e do uso e ocupação irregular do solo. Diante dessa nova ordem mundial, tem-se difundido a importância de se discutir o planejamento e o desenvolvimento das paisagens urbanas no âmbito da ecologia da paisagem.

A zona urbana pode ser dividida em três grandes sistemas: o sistema de espaço com construções, o sistema de espaços de integração urbana e os sistemas livres de construção. Nesse último estão as áreas verdes $(\mathrm{AVs})$, consideradas um tipo especial de área livre cujo elemento fundamental de composição é a vegetação (Cavalheiro et al., 1999). Segundo Biondi (2015), as AVs como componentes da floresta urbana pública são o produto de um processo paisagístico que pode apresentar diferentes graus de antropização.

As AVs são componentes estruturais da paisagem urbana, desempenhando funções ecológicas e sociais que resultam na melhoria do bem-estar e da qualidade de vida do homem (Lang \& Blaschke, 2009). Entretanto, o papel desempenhado pelos espaços verdes nas cidades brasileiras tem sido uma consequência de necessidades, preferências e costumes momentâneos da sociedade.

Embora todas as cidades brasileiras apresentem AVs (públicas) onde a população pode desfrutar de lazer e contato com a natureza, poucas têm tais espaços de forma organizada e planejada (Milano \& Dalcin, 2000), de modo que acabam não passando de espaços dispersos pela malha urbana (Loboda \& De Angelis, 2005).

A cidade de Curitiba tem histórico de capital ecológica, resultado de constantes e incansáveis projetos e propagandas políticas. Curitiba iniciou no século XIX sua arborização com o plantio das primeiras árvores em ruas e praças (Biondi \& Althaus, 2005; Curitiba, 2008). Em 1875 inaugurou o primeiro parque da cidade, o Passeio Público. Em 1966, a lei municipal n. 2.626 definiu e implantou o plano diretor da cidade, o qual conduz o seu crescimento associado à preservação das AVs diretamente relacionado à qualidade de vida dos cidadãos (Curitiba, 2008). O zoneamento e o uso do solo foram estabelecidos em 1975, instituindo a conservação das áreas naturais como prioritária para o crescimento da cidade (Curitiba, 1975). Em 2000 foi feita a revisão do zoneamento e aprovadas as leis do Sistema Municipal de Unidades de Conservação (SNUCM) (Curitiba, 2000a) e do código florestal do município (Curitiba, 2000b).

Dados do ano de 2014 do Instituto de Pesquisa e Planejamento Urbano de Curitiba (IPPUC) indicam que a cidade possui mais de mil AVs e 300 mil árvores de rua (Curitiba, 2008, 2014). Segundo estudo de Vieira \& Biondi (2008), a cobertura vegetal da cidade de Curitiba, entre 1986 e 2004, diminuiu de 39\% para $30 \%$ devido ao processo de crescimento urbano.

Estudos quantitativos e qualitativos podem embasar indicadores de qualidade ambiental urbana quando determinam a distribuição, a dimensão espacial e as funções de cada AV na cidade (Caporusso \& Matias, 2008). É preciso considerar a quantidade, qualidade e distribuição das AVs no meio urbano (Matos \& Queiroz, 2009).

Aliado ao estudo da vegetação urbana, o sensoriamento remoto de alta resolução espacial e os sistemas de informações geográficas podem fornecer, em pouco tempo e em larga escala, dados espaciais a partir dos quais a vegetação urbana pode ser identificada, quantificada, qualificada e analisada quanto à sua distribuição espacial.

O presente trabalho teve por objetivo identificar a cobertura de vegetação presente nas diferentes tipologias de AVs de Curitiba e de suas regionais, bem como analisar a configuração espacial dessas na paisagem urbana, podendo contribuir para o planejamento de uso e ocupação do solo no que tange às áreas verdes.

\section{MATERIAL E MÉTODOS}

A área de estudo engloba o município de Curitiba, capital do estado do Paraná, na região sul do Brasil (Figura 1). O marco zero da cidade, localizado na Praça Tiradentes, tem as coordenadas $25^{\circ} 25^{\prime} 41^{\prime \prime}$ de latitude S e $25^{\circ} 25^{\prime} 41^{\prime \prime}$ de longitude W. A cidade ocupa uma área de $432,17 \mathrm{~km}^{2}$ do primeiro planalto paranaense, com altitude média em relação ao nível do mar de 934,6 m e clima subtropical (ou temperado) úmido segundo a classificação de Köppen. Curitiba foi fundada em 1693 e atualmente é dividida em 75 bairros dispostos em 


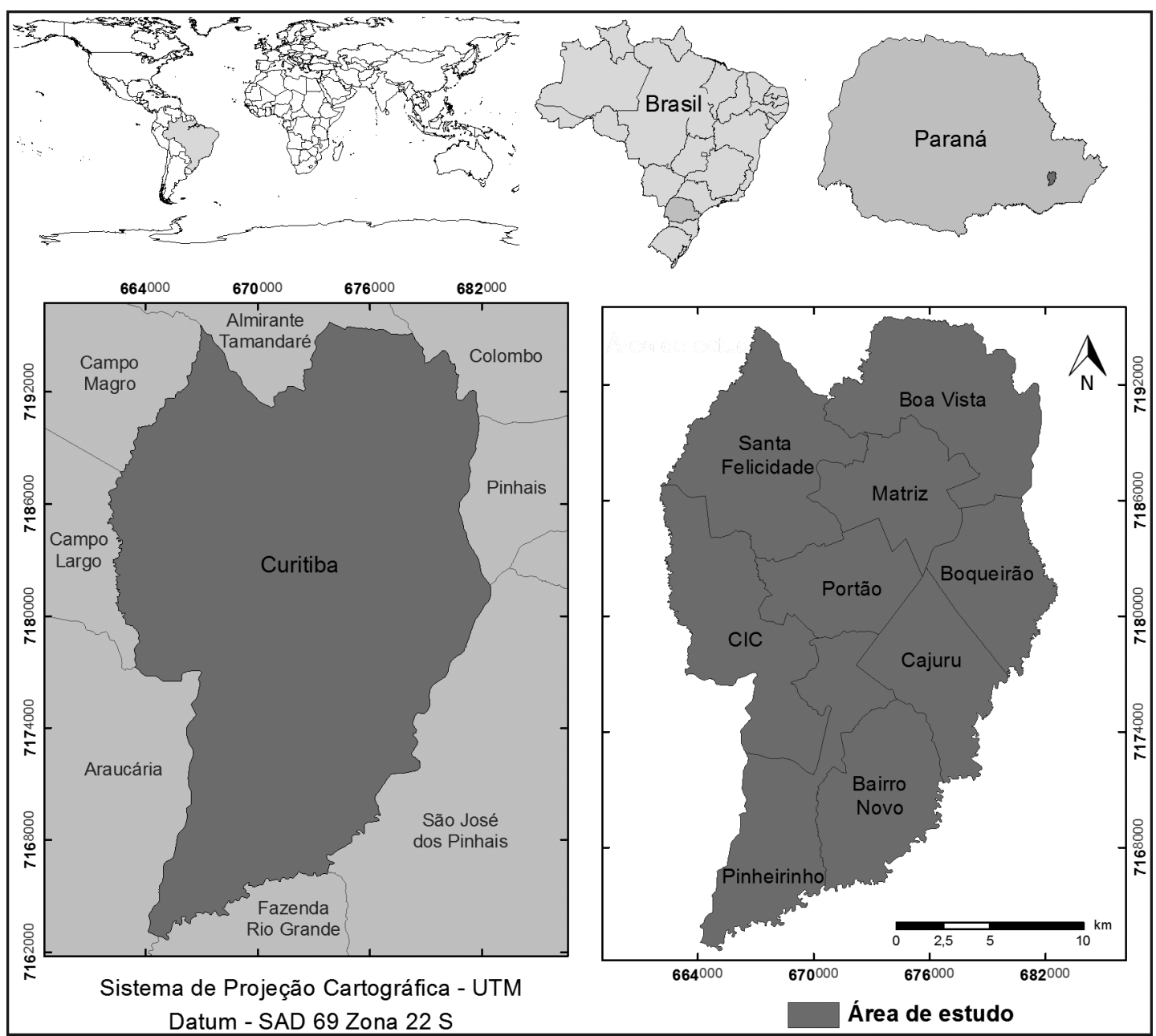

Figura 1. Área de estudo: Curitiba, PR.

Figure 1. Study area location, Curitiba, PR.

9 unidades administrativas ou regionais: Bairro Novo, Boa Vista, Boqueirão, Cajuru, Cidade Industrial de Curitiba (CIC), Matriz, Portão, Pinheirinho e Santa Felicidade (IPPUC, 2014b) (Figura 1).

Para identificar a cobertura de vegetação presente nas AVs de Curitiba foram utilizadas imagens digitais de alta resolução espacial ( $0,5 \mathrm{~m}$ fusionada) do satélite GeoEye-1, datadas de janeiro de 2010. As AVs foram definidas a partir de um arquivo digital contendo uma base de dados vetoriais de informações diversas como as AVs e a hidrografia, datado de 2010, elaborado e fornecido pelo IPPUC (2014a).

Para a classificação das imagens digitais foi construída uma árvore de decisão na qual um conjunto de regras de decisão foi estabelecido, baseado no comportamento da vegetação realçada pela técnica do Índice de Vegetação por Diferença Normalizada (Normalized Difference Vegetation Index - NDVI). Para eliminar as áreas de superfícies azuis e as áreas de sombra, cujo comportamento é semelhante ao da vegetação no NDVI, foi utilizada a transformação por Componentes Principais (CP) e a transformação em espaço de cores - matiz, saturação e valor (hue, saturation, value - HSV). O NDVI e a transformação em HSV foram processados no software ENVI, a transformação por CP foi realizada no software MultiSpec. A classificação com as regras de decisão foi programada para ser processada no software MATLAB.

O processamento da imagem classificada e o pós-processamento foram realizados em ambiente computacional SIG no software ArcGIS 10. Foi considerada 
cobertura de vegetação em área verde toda a vegetação (independente do porte) inserida nos polígonos indicados no arquivo vetorial de 2010 fornecido pelo IPPUC (2014a). Esse arquivo digital conteve as seguintes tipologias de AVs: bosque, centro poliesportivo, eixo de animação, jardim ambiental, jardinete, largo, núcleo ambiental, parque, praça. Além dessas categorias, o arquivo digital conteve polígonos com a denominação de "área verde diversa" e "praças ou jardinetes", sem especificação exata de tipologia.

A imagem utilizada na realização dessa pesquisa data de 2010, portanto, foi utilizado um arquivo de base de dados vetoriais contendo as AVs de Curitiba, também datado de 2010. Dessa forma, algumas AVs criadas após meados de 2010 não foram contempladas como, por exemplo, as Reservas Particulares do Patrimônio Natural Municipal - RPPNM.

O arquivo resultante da classificação da cobertura de vegetação foi transformado do formato matricial para vetorial. Com as informações vetorizadas obteve-se acesso aos dados da tabela de atributos, onde foi calculada a área dos polígonos de vegetação. Também foram calculadas as áreas dos polígonos que representaram cada uma das AVs constantes no arquivo vetorial do IPPUC. Esses dados foram organizados quanto à tipologia de $\mathrm{AV}$, tanto para totalidade da cidade de Curitiba quanto para suas regionais. A compilação de todos os dados obtidos, bem como o seu processamento, foram realizados em planilha comum de dados do software Excel.

\section{RESULTADOS E DISCUSSÃO}

\subsection{Análise das áreas verdes com base no arquivo vetorial do IPPUC}

$\mathrm{O}$ arquivo digital, fornecido e elaborado pelo IPPUC, contendo as AVs de Curitiba no ano de 2010, apresentou um total de $1.173 \mathrm{AVs}$, cobrindo uma área de $19.035 .324,37 \mathrm{~m}^{2}$ ou $4,38 \%$ da área total da cidade.

Foram identificados 16 bosques, 1 centro poliesportivo, 22 eixos de animação, 2 jardins ambientais, 393 jardinetes, 54 largos, 29 núcleos ambientais, 21 parques ( 2 denominados parques lineares), 418 praças, 147 "áreas verdes diversas" e 70 "praças ou jardinetes", essas duas últimas indicadas no arquivo vetorial do IPPUC (2014a), entretanto sem especificação exata de tipologia. Salientando que o arquivo utilizado data de 2010 e, portanto, as AVs criadas após essa data não foram contempladas.

\subsection{Análise da cobertura de vegetação presente nas áreas verdes}

Do total de 1.173 AVs, 1.164 apresentaram alguma cobertura de vegetação e em apenas 9 áreas não foi verificada a presença de vegetação, sendo 5 jardinetes, 3 praças e 1 largo (Tabela 1).

Jardinete é uma tipologia de AV estipulada e regulamentada pelo decreto $n$. 427/1983, que define critérios para a denominação de áreas públicas ajardinadas (Curitiba, 1983). No referido decreto, a definição de jardinete se limita a mencionar que são áreas com até $2.500 \mathrm{~m}^{2}$. Essa definição é muito simplificada, entretanto, por estar contida em um decreto que objetiva áreas públicas ajardinadas, subentende-se que deveriam ser áreas com alguma cobertura de vegetação. Apesar disso, 5 jardinetes não apresentaram cobertura de vegetação. Para Buccheri (2010), a definição simplista acaba por permitir que qualquer área não aproveitada para qualquer outro fim, mas que seja pública, possa se transformar ou ser chamada de jardinete, sobre os quais pode se apontar falta de interesse e/ou importância da prefeitura para com esse tipo de espaço. Para Viezzer (2014), as diferenças entre as tipologias praça e jardinete se perdem ou no mínimo se confundem. Para a autora, a necessidade da criação da tipologia jardinete é questionável.

Nas praças e largos, devido a sua característica cultural (Biondi, 2015), a vegetação não é requisito essencial na sua composição (Puppi, 1981). Até nas mais famosas praças do mundo, a vegetação está ausente devido à necessidade de uma maior capacidade para as grandes concentrações humanas, pela intensa circulação ou outras razões de ordem prática. Entretanto, prevalece o conceito de praça arborizada (Puppi, 1981).

\section{3. Área de cobertura versus cobertura de vegetação presente nas áreas verdes}

A área total de cobertura de vegetação nas AVs foi de $14.024 .982,43 \mathrm{~m}^{2}$, ou seja, 73,68\% da área de cobertura do solo das AVs de Curitiba são efetivamente cobertas por vegetação (Tabela 1, Figura 2). 
Tabela 1. Tipologia de áreas verdes e respectivas quantidades, área de cobertura total, área de cobertura de vegetação e área de corpos d'água sem cobertura de vegetação.

Table 1. Green areas typologies and their quantity, full coverage area, vegetation coverage area and water area without vegetation cover.

\begin{tabular}{|c|c|c|c|c|c|c|c|}
\hline $\begin{array}{l}\text { Tipologia de } \\
\text { áreas verdes }\end{array}$ & $\mathbf{N}^{\circ}$ & $\begin{array}{l}\mathbf{N}^{\circ} \\
(\%)\end{array}$ & $\begin{array}{l}\text { Área total } \\
\qquad\left(\mathbf{m}^{2}\right)\end{array}$ & $\begin{array}{c}\text { Área } \\
\text { coberta por } \\
\text { vegetação } \\
\left(\mathbf{m}^{2}\right)\end{array}$ & $\begin{array}{c}\text { Área } \\
\text { coberta por } \\
\text { vegetação } \\
(\%)\end{array}$ & $\begin{array}{c}\text { Corpos d'água } \\
\text { sem cobertura } \\
\text { de vegetação } \\
\left(\mathbf{m}^{2}\right)\end{array}$ & $\begin{array}{c}\text { Área coberta } \\
\text { por vegetação } \\
\text { e hidrografia } \\
\left(\mathrm{m}^{2}\right)\end{array}$ \\
\hline $\begin{array}{l}\text { Centro } \\
\text { Poliesportivo }\end{array}$ & 1 & 0,09 & $341.841,31$ & $325.746,22$ & 95,29 & 0,00 & $325.746,22$ \\
\hline Jardim Ambiental & 2 & 0,17 & $21.879,05$ & $14.993,09$ & 68,53 & 0,00 & $14.993,09$ \\
\hline Bosque & 16 & 1,36 & $894.907,33$ & $777.014,71$ & 86,83 & $5.499,94$ & $782.514,66$ \\
\hline Parque & 21 & 1,79 & $10.544 .488,73$ & $7.892 .277,79$ & 74,85 & $1.134 .908,56$ & $9.027 .186,36$ \\
\hline Eixo de Animação & 22 & 1,88 & $358.338,46$ & $266.258,63$ & 74,30 & 150,95 & $266.409,57$ \\
\hline Núcleo Ambiental & 29 & 2,47 & $18.301,23$ & $10.137,88$ & 55,39 & 0,00 & $10.137,88$ \\
\hline Largo & 53 & 4,52 & $57.477,31$ & $35.689,68$ & 62,09 & 0,00 & $35.689,68$ \\
\hline Praça ou Jardinete & 67 & 5,71 & $159.135,77$ & $62.684,37$ & 39,39 & $4.052,81$ & $66.737,18$ \\
\hline Área verde diversa & 147 & 12,53 & $2.892 .286,79$ & $2.347 .793,36$ & 81,17 & $4.075,01$ & $2.351 .868,38$ \\
\hline Jardinete & 388 & 33,08 & $533.381,93$ & $322.326,44$ & 60,43 & 26,91 & $322.353,35$ \\
\hline Praça & 418 & 35,64 & $3.215 .284,92$ & $1.972 .181,92$ & 61,34 & $2.997,15$ & $1.975 .179,07$ \\
\hline $\begin{array}{l}\text { AVs sem } \\
\text { vegetação }\end{array}$ & 9 & 0,77 & $3.289,23$ & 0,0 & 0 & 0,0 & 0 \\
\hline Total & 1173 & 100 & $19.040 .612,07$ & $14.027 .104,10$ & $73,68 \%$ & $1.151 .711,34$ & $15.178 .815,44$ \\
\hline
\end{tabular}

A presença de corpos d'água nas AVs foi estimada em 1.952.922,65 $\mathrm{m}^{2}$, sendo 6,05\% sem cobertura de vegetação (Tabela 1, Figura 2). Os corpos d'água foram também quantificados, uma vez que são componentes naturais importantes das AVs, principalmente por agregarem área permeável a esses ambientes, e se somados à área coberta por vegetação, Curitiba apresenta cerca de $80 \%$ da cobertura do solo de suas AVs permeável.

Cavalheiro et al. (1999), em boletim informativo da Sociedade Brasileira de Arborização Urbana (SBAU), recomendam que as AVs deveriam atender a três objetivos principais: ecológico-ambiental, estético e de lazer. Para tal, pelo menos $70 \%$ do seu espaço deveriam ser constituídos por áreas vegetadas com solo permeável. Quando analisado o resultado obtido para a totalidade de AVs de Curitiba, ou seja, 73,68\% da área das AVs cobertas por vegetação e $80 \%$ da área das AVs de solo permeável, então as AVs de Curitiba podem ser consideradas adequadamente cobertas por áreas vegetadas, segundo recomendação da SBAU.

Entretanto, quando feita a análise por tipologia de $\mathrm{AV}$, as categorias jardim ambiental, núcleo ambiental, largo, "praça ou jardinete", jardinete e praça apresentaram área de cobertura de vegetação abaixo de 70\%, que é o valor mínimo recomendado pela SBAU.

As categorias jardim ambiental e núcleo ambiental são tipologias utilizadas pela prefeitura municipal de Curitiba, entretanto não existe definição específica para essas em lei ou decreto. Segundo Buccheri (2010), o departamento de parques e praças de Curitiba considera como núcleo ambiental o cruzamento de ruas fechadas para o trânsito, no qual somente é feito um paisagismo; e como jardim ambiental, uma área composta por trechos de ruas fechadas para o trânsito (com acesso para moradores), onde são instalados equipamentos de lazer. Ao passo que os largos, jardinetes e praças são AVs de caráter cultural, nas quais a maior prioridade são as atividades sociais (Biondi, 2015). Portanto, todas essas categorias que apresentam valores de cobertura de vegetação abaixo do recomendado, podem ser consideradas AVs cuja presença de vegetação não é fator essencial (Puppi, 1981) devido às funções cultural, social (Biondi, 2015) e estrutural que exercem.

Dentre as tipologias de AVs indicadas no arquivo vetorial do IPPUC, mais de dois terços do número total são praças e jardinetes, entretanto essas representam apenas $16,35 \%$ da cobertura de vegetação presente 


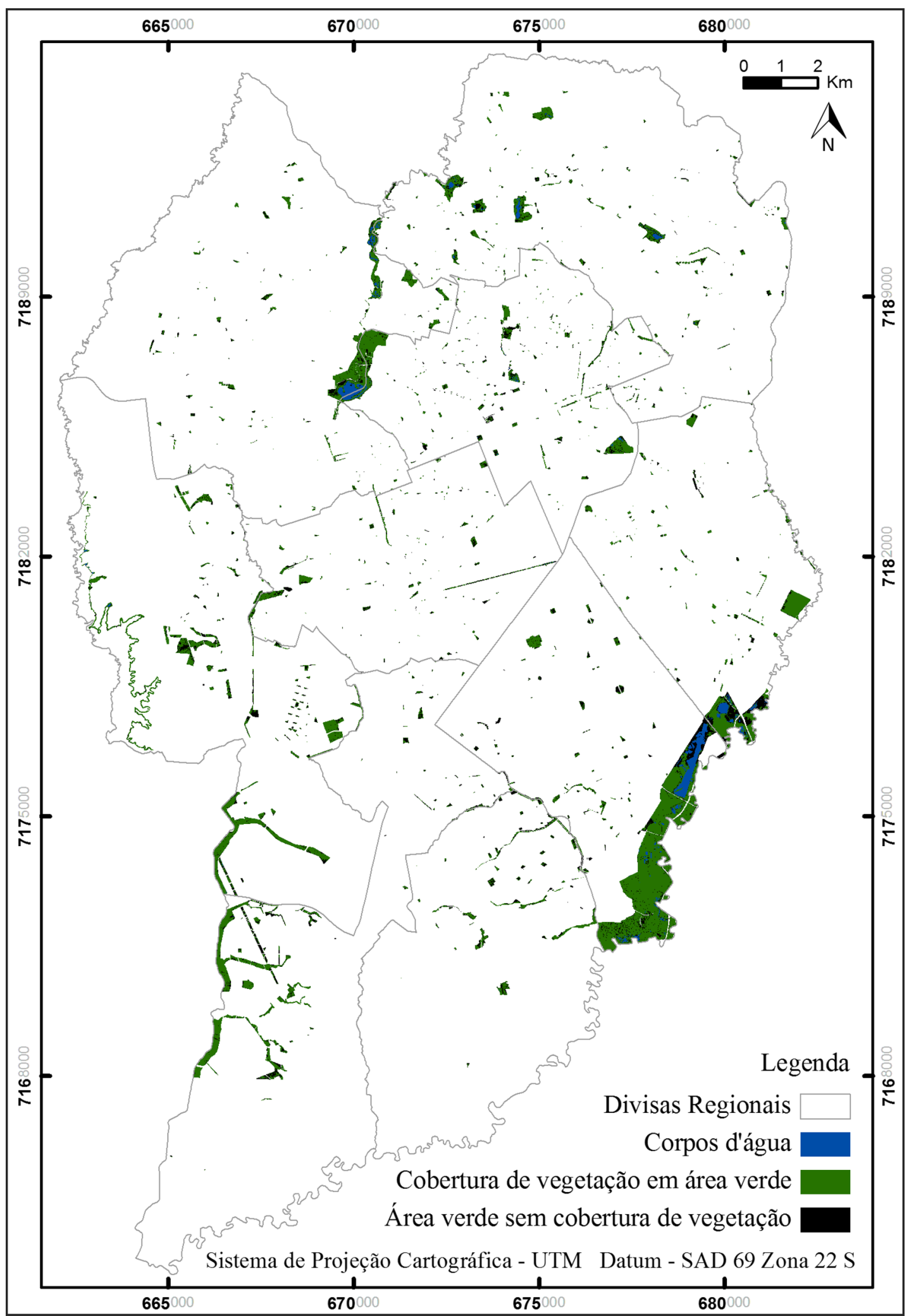

Figura 2. Distribuição e cobertura de vegetação das áreas verdes de Curitiba, PR.

Figure 2. Green areas' distribution and vegetation cover in Curitiba, PR. 
nas AVs (Tabela 1). O decreto n. 427/83, que define os critérios para a denominação de áreas públicas ajardinadas considera as praças como áreas públicas ajardinadas com mais de $2.500 \mathrm{~m}^{2}$ e os jardinetes com área até $2.500 \mathrm{~m}^{2}$ (Curitiba, 1983), ambas de pequeno porte. Portanto, apesar da grande quantidade de AVs dessas tipologias, a representatividade de sua cobertura de vegetação não é altamente expressiva e não garante a presença de cobertura de vegetação na cidade. Entretanto, são extremamente importantes quanto às suas funções, principalmente social e de caráter cultural para a cidade (Biondi, 2015). Quando somadas as áreas das praças e largos de Curitiba, elas representam $0,75 \%$ da cidade, e se considerada apenas a cobertura de vegetação, esse valor cai para $0,46 \%$, ainda que as praças sejam a categoria de AV de maior representatividade na paisagem de Curitiba.

“Áreas verdes diversas" e "praças ou jardinetes” são AVs indicadas no arquivo vetorial do IPPUC, entretanto sem especificação exata de tipologia. São 214 AVs com cobertura de vegetação (ou 18,49\% do número total de AV de Curitiba) cuja categoria e função não são especificadas, porém são consideradas e contabilizadas pelo IPPUC. Isso indica uma dificuldade de planejamento e até mesmo de atenção ou monitoramento dos órgãos competentes, pois sequer existe uma tipologia estipulada para essas áreas que representam $17,18 \%$ da cobertura total de vegetação em AVs da cidade (Tabela 1).

As categorias largo, núcleo ambiental, eixo de animação, jardim ambiental e centro poliesportivo representam menos de $5 \%$ do total de cobertura de vegetação em AV.

Curitiba possui apenas $37 \mathrm{AVs}$ (3,15\% do número total de AVs) entre as tipologias parques e bosques, entretanto, quando considerada a quantidade de cobertura de vegetação, esses detêm mais da metade $(61,80 \%)$ da área total de cobertura de vegetação presente nas AVs da cidade (Tabela 1). Heckmann et al. (2008) afirmam que remanescentes de florestas nativas contribuem significativamente para manter espécies nativas em áreas urbanas. O parque Barigui, por exemplo, foi apontado por Kozera et al. (2006) como um fragmento remanescente de floresta ombrófila mista com grande riqueza de espécies vegetais vasculares, mesmo encontrando-se em área urbana com interferência antrópica. Portanto, já que os parques e bosques são as categorias do SNUCM formadas pelas mais expressivas áreas de vegetação nativa remanescente nas cidades, o número dessas áreas para a cidade de Curitiba é muito baixo por se tratar das tipologias de AVs mais importantes na paisagem.

Segundo Nucci (2008), a quantidade e a qualidade das AVs nas cidades brasileiras são insuficientes. Os resultados aqui apresentados corroboram com Nucci (2008). Considerando-se que Curitiba possui 1.751.907 habitantes, segundo o último censo do Instituto Brasileiro de Geografia e Estatística (IBGE, 2010), são 47.348,83 habitantes para cada parque ou bosque da cidade.

Quando observada a porcentagem de área de cobertura de vegetação entre as diferentes tipologias de $\mathrm{AV}$, essa se mostra coerente à função de cada uma delas na cidade. As praças possuem a menor proporção de vegetação por área, o que é esperado, pelo caráter cultural dessa tipologia (Biondi, 2015) e até mesmo pelo fato de existirem praças desprovidas de cobertura de vegetação na cidade, conforme constatado nessa pesquisa (Figura 3). As tipologias que apresentam maior proporção de vegetação são os parques e bosques, que são consideradas as mais importantes para a conservação dos remanescentes florestais urbanos.

\subsection{Análise por regional da distribuição espacial das AVs e sua cobertura de vegetação}

A regional Matriz apresentou a maior diversidade de tipologias de AVs constantes no arquivo do IPPUC e o maior número de AVs das tipologias praça, jardinete e largo (Tabela 2). Essa é a regional de ocupação mais antiga e central da cidade, o que pode justificar essa maior concentração de AVs de caráter cultural (Biondi, 2015).

As regionais Portão, Bairro Novo, Matriz e Boa Vista apresentaram menos de 70\% da área de cobertura do solo de suas AVs coberta por vegetação (Tabela 2), o que pode ser considerado pouco ou insuficiente segundo o proposto pela SBAU (Cavalheiro et al., 1999) (Figura 4). Quando agregada à quantidade de cobertura de vegetação, os valores referentes à cobertura do solo formados pelos corpos d'água, somente as regionais Portão e Bairro Novo apresentam menos de 70\% da área total de suas AVs permeáveis.

A regional CIC foi a que apresentou a maior proporção de vegetação em AVs, cerca de 80,62\% (Tabela 2, Figura 4). Essa regional detém 6 parques e 
Tabela 2. Tipologia de áreas verdes e respectiva quantidade, área de cobertura total, área de cobertura de vegetação e área de corpos d'água sem cobertura de vegetação por Regional de Curitiba, PR.

Table 2. Green areas typologies and their quantity, coverage area, vegetation coverage area and water area without vegetation cover for Regional in Curitiba-PR.

\begin{tabular}{|c|c|c|c|c|c|}
\hline $\begin{array}{l}\text { Tipologia de } \\
\text { áreas verdes }\end{array}$ & $\mathbf{N}$ & $\begin{array}{l}\text { Área total } \\
\qquad\left(\mathrm{m}^{2}\right)\end{array}$ & $\begin{array}{c}\text { Área coberta } \\
\text { por vegetação } \\
\left(\mathbf{m}^{2}\right)\end{array}$ & $\begin{array}{c}\text { Corpos d'água } \\
\text { sem cobertura } \\
\text { de vegetação } \\
\left(\mathbf{m}^{2}\right)\end{array}$ & $\begin{array}{c}\text { Área coberta por } \\
\text { vegetação e } \\
\text { hidrografia }\left(\mathrm{m}^{2}\right)\end{array}$ \\
\hline \multicolumn{6}{|l|}{ Bairro Novo } \\
\hline Área verde diversa & 26 & $316.024,02$ & $220.216,82$ & 7,67 & $220.224,49$ \\
\hline Bosque & 1 & $66.842,41$ & $48.444,01$ & 0,00 & $48.444,01$ \\
\hline Eixo de Animação & 3 & $16.552,98$ & $12.632,14$ & 0,00 & $12.632,14$ \\
\hline Jardinete & 6 & $3.827,23$ & $1.455,62$ & 0,00 & $1.455,62$ \\
\hline Largo & 0 & 0,00 & 0,00 & 0,00 & 0,00 \\
\hline Núcleo Ambiental & 0 & 0,00 & 0,00 & 0,00 & 0,00 \\
\hline Parque & 1 & $71.902,73$ & $52.441,11$ & 704,91 & $53.146,03$ \\
\hline Praça & 24 & $255.238,30$ & $147.686,93$ & 0,01 & $147.686,94$ \\
\hline Praça ou Jardinete & 5 & $15.915,21$ & $4.807,62$ & 0,00 & $4.807,62$ \\
\hline Total & 66 & 746302,88 & 487684,24 & 712,64 & 488396,85 \\
\hline \multicolumn{6}{|l|}{ Boa Vista } \\
\hline Área verde diversa & 7 & $86.701,75$ & $77.426,32$ & $2.295,37$ & $79.721,69$ \\
\hline Bosque & 4 & $111.221,31$ & $85.609,73$ & $4.648,78$ & $90.258,51$ \\
\hline Eixo de Animação & 6 & $71.846,12$ & $46.265,64$ & 56,64 & $46.322,28$ \\
\hline Jardinete & 76 & $129.855,09$ & $81.601,71$ & 0,00 & $81.601,71$ \\
\hline Largo & 3 & $2.925,41$ & $1.860,10$ & 0,00 & $1.860,10$ \\
\hline Núcleo Ambiental & 8 & $3.371,75$ & $1.983,31$ & 0,00 & $1.983,31$ \\
\hline Parque & 7 & $932.688,21$ & $664.133,95$ & $110.644,04$ & $774.777,99$ \\
\hline Praça & 66 & $292.196,28$ & $176.491,08$ & 0,00 & $176.491,08$ \\
\hline Praça ou Jardinete & 14 & $24.909,86$ & $9.826,23$ & 0,00 & $9.826,23$ \\
\hline Total & 191 & 1655715,78 & 1145198,06 & 117644,82 & 1262842,89 \\
\hline \multicolumn{6}{|l|}{ Boqueirão } \\
\hline Área verde diversa & 6 & $53.103,06$ & $38.035,45$ & 0,00 & $38.035,45$ \\
\hline Bosque & 1 & $90.995,25$ & $83.921,46$ & 0,00 & $83.921,46$ \\
\hline Eixo de Animação & 0 & 0,00 & 0,00 & 0,00 & 0,00 \\
\hline Jardinete & 23 & $43.502,62$ & $20.995,07$ & 0,00 & $20.995,07$ \\
\hline Largo & 0 & 0,00 & 0,00 & 0,00 & 0,00 \\
\hline Núcleo Ambiental & 1 & 226,12 & 143,55 & 0,00 & 143,55 \\
\hline Parque & 1 & $6.292 .048,35$ & $4.737 .669,44$ & $556.415,37$ & $5.294 .084,81$ \\
\hline Praça & 42 & $407.711,68$ & $216.075,33$ & 1,00 & $216.076,33$ \\
\hline Praça ou Jardinete & 4 & $15.936,15$ & $3.504,94$ & 0,00 & $3.504,94$ \\
\hline Total & 78 & 6903523,23 & 5100345,24 & 556416,36 & 5656761,61 \\
\hline \multicolumn{6}{|l|}{ Cajuru } \\
\hline Área verde diversa & 9 & $27.760,80$ & $22.414,90$ & 32,71 & $22.447,61$ \\
\hline Bosque & 1 & $42.936,69$ & $41.017,03$ & 0,00 & $41.017,03$ \\
\hline Centro Poliesportivo* & 1 & $341.841,31$ & $325.746,22$ & 0,00 & $325.746,22$ \\
\hline Eixo de Animação & 2 & $12.271,32$ & $10.350,46$ & 0,00 & $10.350,46$ \\
\hline Jardinete & 39 & $56.588,51$ & $40.420,42$ & 0,00 & $40.420,42$ \\
\hline Largo & 0 & 0,00 & 0,00 & 0,00 & 0,00 \\
\hline Núcleo Ambiental & 2 & $1.388,82$ & 897,33 & 0,00 & 897,33 \\
\hline Parque & 2 & $116.025,68$ & $67.256,58$ & $150.748,98$ & $218.005,56$ \\
\hline Praça & 48 & $268.611,90$ & $178.862,99$ & 0,00 & $178.862,99$ \\
\hline
\end{tabular}

*Tipologia presente somente nesta Regional. 
Tabela 2. Continuação...

Table 2. Continued...

\begin{tabular}{|c|c|c|c|c|c|}
\hline $\begin{array}{l}\text { Tipologia de } \\
\text { áreas verdes }\end{array}$ & $\mathbf{N}$ & $\begin{array}{l}\text { Área total } \\
\qquad\left(\mathbf{m}^{2}\right)\end{array}$ & $\begin{array}{c}\text { Área coberta } \\
\text { por vegetação } \\
\qquad\left(\mathbf{m}^{2}\right)\end{array}$ & $\begin{array}{c}\text { Corpos d'água } \\
\text { sem cobertura } \\
\text { de vegetação } \\
\left(\mathbf{m}^{2}\right)\end{array}$ & $\begin{array}{c}\text { Área coberta por } \\
\text { vegetação e } \\
\text { hidrografia }\left(\mathrm{m}^{2}\right)\end{array}$ \\
\hline Praça ou Jardinete & 2 & $12.230,60$ & $1.694,51$ & 0,00 & $1.694,51$ \\
\hline Total & 106 & 879655,61 & 688660,43 & 150781,69 & 839442,12 \\
\hline \multicolumn{6}{|l|}{ CIC } \\
\hline Área verde diversa & 25 & $1.009 .389,41$ & $873.854,89$ & $1.729,11$ & $875.584,00$ \\
\hline Bosque & 2 & $234.125,45$ & $213.406,55$ & 83,47 & $213.490,03$ \\
\hline Eixo de Animação & 3 & $23.660,55$ & $16.679,96$ & 40,78 & $16.720,74$ \\
\hline Jardinete & 21 & $42.119,63$ & $24.256,99$ & 0,00 & $24.256,99$ \\
\hline Largo & 0 & 0,00 & 0,00 & 0,00 & 0,00 \\
\hline Núcleo Ambiental & 0 & 0,00 & 0,00 & 0,00 & 0,00 \\
\hline Parque & 5 & $989.817,48$ & $821.454,96$ & $11.133,40$ & $832.588,36$ \\
\hline Praça & 53 & $459.708,14$ & $277.357,60$ & 244,16 & $277.601,75$ \\
\hline Praça ou Jardinete & 6 & $4.668,94$ & 883,58 & 0,00 & 883,58 \\
\hline Total & 115 & 2763489,60 & 2227894,52 & 13230,92 & 2241125,45 \\
\hline \multicolumn{6}{|l|}{ Matriz } \\
\hline Área verde diversa & 0 & 0,00 & 0,00 & 0,00 & 0,00 \\
\hline Bosque & 2 & $79.592,21$ & $75.009,88$ & 2,06 & $75.011,94$ \\
\hline Eixo de Animação & 2 & $18.173,39$ & $15.675,66$ & 26,50 & $15.702,15$ \\
\hline Jardim Ambiental $^{*}$ & 2 & $21.879,05$ & $14.993,09$ & 0,00 & $14.993,09$ \\
\hline Jardinete & 83 & $81.530,83$ & $54.317,88$ & 0,00 & $54.317,88$ \\
\hline Largo & 34 & $35.890,89$ & $21.189,63$ & 0,00 & $21.189,63$ \\
\hline Núcleo Ambiental & 12 & $8.739,87$ & $5.110,75$ & 0,00 & $5.110,75$ \\
\hline Parque & 3 & $897.707,33$ & $656.566,27$ & $93.956,09$ & $750.522,36$ \\
\hline Praça & 84 & $524.295,74$ & $293.378,45$ & $2.313,20$ & $295.691,65$ \\
\hline Praça ou Jardinete & 11 & $20.971,19$ & $10.997,68$ & $1.589,65$ & $12.587,33$ \\
\hline Total & 233 & 1688780,50 & 1147239,28 & 97887,49 & 1245126,78 \\
\hline \multicolumn{6}{|l|}{ Pinheirinho } \\
\hline Área verde diversa & 58 & $1.272 .452,48$ & $1.010 .815,98$ & 10,15 & $1.010 .826,13$ \\
\hline Bosque & 0 & 0,00 & 0,00 & 0,00 & 0,00 \\
\hline Eixo de Animação & 3 & $93.688,86$ & $82.551,19$ & 0,00 & $82.551,19$ \\
\hline Jardinete & 21 & $21.875,90$ & $8.479,45$ & 0,00 & $8.479,45$ \\
\hline Largo & 2 & $2.137,53$ & $1.232,70$ & 0,00 & $1.232,70$ \\
\hline Núcleo Ambiental & 0 & 0,00 & 0,00 & 0,00 & 0,00 \\
\hline Parque & 0 & 0,00 & 0,00 & 0,00 & 0,00 \\
\hline Praça & 24 & $486.956,31$ & $365.106,12$ & 276,46 & $365.382,58$ \\
\hline Praça ou Jardinete & 6 & $19.986,19$ & $7.524,83$ & 0,00 & $7.524,83$ \\
\hline Total & 114 & 1897097,28 & 1475710,26 & 286,61 & 1475996,87 \\
\hline \multicolumn{6}{|l|}{ Portão } \\
\hline Área verde diversa & 0 & 0,00 & 0,00 & 0,00 & 0,00 \\
\hline Bosque & 1 & $66.157,50$ & $58.557,77$ & 0,00 & $58.557,77$ \\
\hline Eixo de Animação & 2 & $111.911,33$ & $74.079,84$ & 2,51 & $74.082,35$ \\
\hline Jardinete & 63 & $62.760,79$ & $32.975,20$ & 26,91 & $33.002,11$ \\
\hline Largo & 10 & $12.889,50$ & $9.561,45$ & 0,00 & $9.561,45$ \\
\hline Núcleo Ambiental & 5 & $3.197,93$ & $1.170,00$ & 0,00 & $1.170,00$ \\
\hline Parque & 2 & $160.337,30$ & $121.392,73$ & 0,00 & $121.392,73$ \\
\hline Praça & 37 & $280.721,12$ & $164.184,98$ & 55,99 & $164.240,97$ \\
\hline
\end{tabular}

${ }^{*}$ Tipologia presente somente nesta Regional. 
Tabela 2. Continuação...

Table 2. Continued...

\begin{tabular}{|c|c|c|c|c|c|}
\hline $\begin{array}{l}\text { Tipologia de } \\
\text { áreas verdes }\end{array}$ & $\mathbf{N}$ & $\begin{array}{l}\text { Área total } \\
\qquad\left(\mathbf{m}^{2}\right)\end{array}$ & $\begin{array}{c}\text { Área coberta } \\
\text { por vegetação } \\
\qquad\left(\mathbf{m}^{2}\right)\end{array}$ & $\begin{array}{l}\text { Corpos d'água } \\
\text { sem cobertura } \\
\text { de vegetação } \\
\left(\mathbf{m}^{2}\right)\end{array}$ & $\begin{array}{c}\text { Área coberta por } \\
\text { vegetação e } \\
\text { hidrografia }\left(\mathbf{m}^{2}\right)\end{array}$ \\
\hline Praça ou Jardinete & 10 & $30.034,09$ & $13.708,16$ & $2.463,16$ & $16.171,32$ \\
\hline Total & 130 & 728009,56 & 475630,12 & 2548,58 & 478178,70 \\
\hline \multicolumn{6}{|l|}{ Santa Felicidade } \\
\hline Área verde diversa & 16 & $126.855,28$ & $105.029,01$ & 0,00 & $105.029,01$ \\
\hline Bosque & 4 & $203.036,50$ & $171.048,29$ & 765,63 & $171.813,92$ \\
\hline Eixo de Animação & 1 & $10.233,90$ & $8.023,73$ & 24,52 & $8.048,25$ \\
\hline Jardinete & 56 & $91.321,33$ & $57.824,11$ & 0,00 & $57.824,11$ \\
\hline Largo & 4 & $3.633,97$ & $1.845,80$ & 0,00 & $1.845,80$ \\
\hline Núcleo Ambiental & 1 & $1.376,72$ & 832,94 & 0,00 & 832,94 \\
\hline Parque & 2 & $1.083 .961,66$ & $771.362,75$ & $211.305,77$ & $982.668,52$ \\
\hline Praça & 40 & $239.845,45$ & $153.038,45$ & 106,32 & $153.144,77$ \\
\hline Praça ou Jardinete & 9 & $14.483,55$ & $9.736,81$ & 0,00 & $9.736,81$ \\
\hline Total & 133 & 1774748,36 & 1278741,89 & 212202,23 & 1490944,13 \\
\hline
\end{tabular}

*Tipologia presente somente nesta Regional.

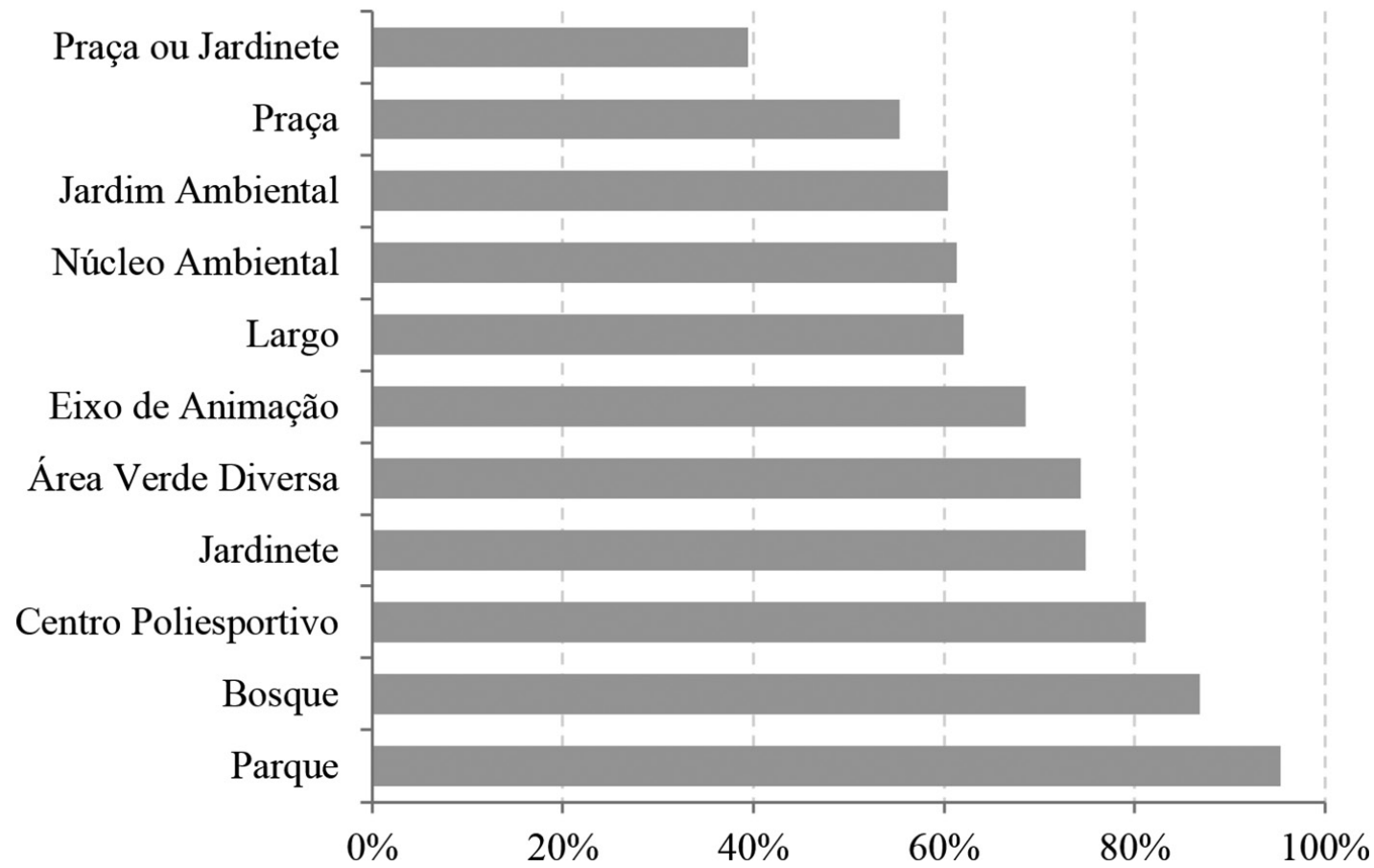

Figura 3. Porcentagem de área de cobertura de vegetação entre as diferentes tipologias de área verde de Curitiba, PR. Figure 3. Vegetation covers area percentage between green area typology in Curitiba, PR.

2 bosques, os quais perfazem $21,62 \%$ do número total dessas tipologias na cidade. Conforme o resultado obtido, de que essas são as tipologias que apresentam a maior cobertura do solo com vegetação, esse elevado número de parques e bosques em relação às outras regionais acabou resultando em uma maior proporção de vegetação em suas AVs. Essa também é a regional mais recente criada em Curitiba, e sua área é em grande 


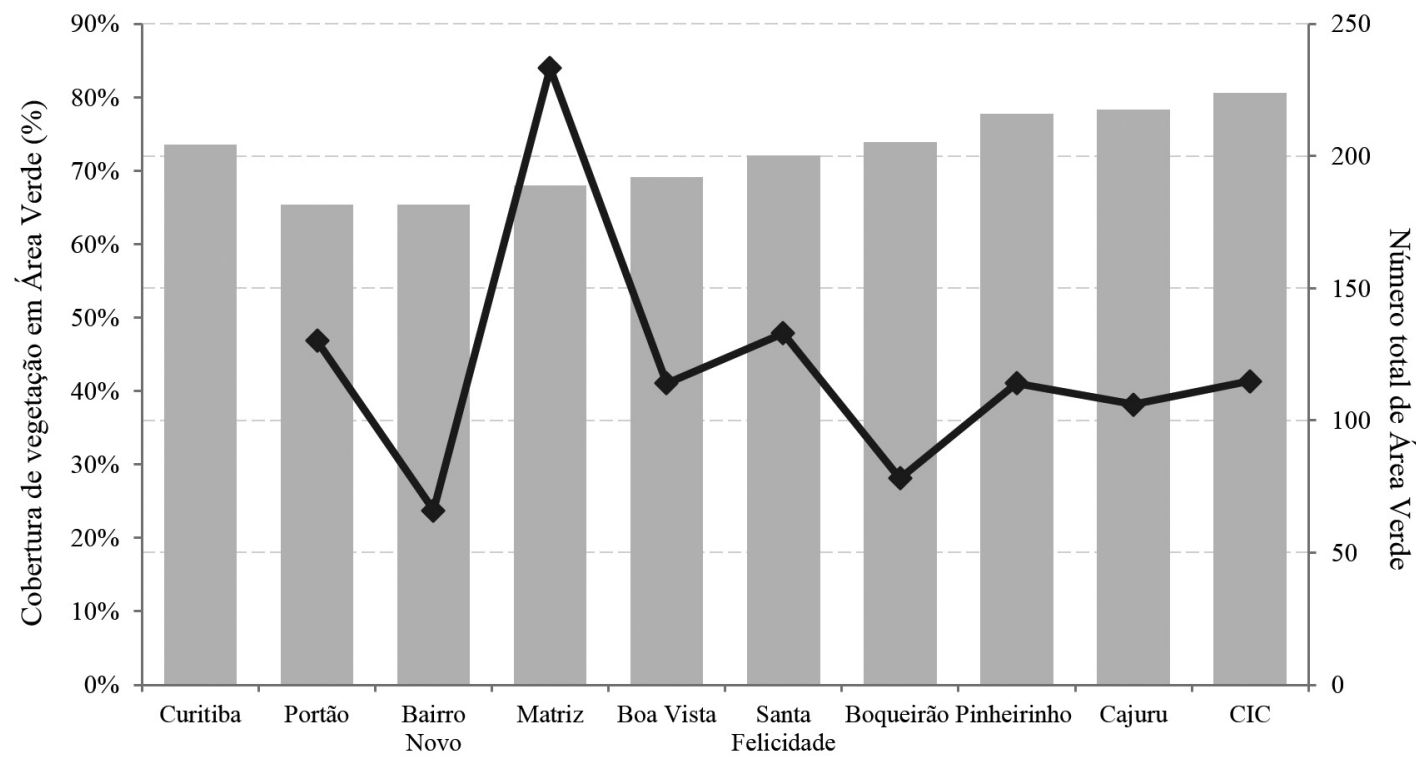

Figura 4. Porcentagem de área de cobertura de vegetação (barras) e número de áreas verdes (pontos) por Regional de Curitiba, PR.

Figure 4. Percentage of vegetation coverage area (bar) and green areas number (points) for Regional in Curitiba, PR.

parte formada por zona de ocupação controlada, zona de contenção, zona de represa e zona industrial (Curitiba, 2000c). Essas categorias de zoneamento acabam resultando em uma baixa densidade populacional (IBGE, 2010), podendo influenciar em uma menor pressão sobre a vegetação.

Com relação às principais categorias de AVs, $54 \%$ do número total dos parques e bosques se localizam nas regionais Boa Vista, Santa Felicidade e Matriz, região norte da cidade, e outros $24 \%$ na regional CIC, região oeste. A regional Pinheirinho não apresentou essas categorias de AVs. A regional Cajuru foi a única que apresentou menos de $70 \%$ da área de seus parques e bosques cobertos por vegetação.

Os resultados apresentados traduzem a discrepância na distribuição das AVs ao longo do município de Curitiba. Duas regionais, CIC e Boa Vista, detém cerca de $50 \%$ do total de parques e bosques da cidade. Categorias essas de maior contribuição à manutenção da conservação da biodiversidade urbana, conforme estabelece o SNUCM de Curitiba (Curitiba, 2000a).

Viezzer et al. (2012) calcularam as porcentagens de cada tipologia de AV em relação à área de cobertura por regional e encontraram resultados variando entre $1 \%$ e $94 \%$. Os resultados corroboram os de Vieira \&
Biondi (2008), verificando que a vegetação de Curitiba já era distribuída de maneira irregular em 1986, fato que se acentuou em 2004. Essa mesma tendência pode ser constada com os resultados obtidos nessa pesquisa para a distribuição da vegetação nas AVs.

\section{CONCLUSÕES}

Com os resultados obtidos conclui-se que a cidade de Curitiba possui menos de $5 \%$ de sua área constituída por AVs, destacando-se a pequena quantidade de parques e bosques, que representam 3,15\% do número total de AVs da cidade.

A maioria das AVs de Curitiba apresenta cobertura de vegetação acima de $70 \%$, sendo que as tipologias de caráter estrutural (jardim ambiental e núcleo ambiental) e cultural (largo, "praça ou jardinete", jardinete e praça) possuem cobertura de vegetação abaixo desse valor, que é o recomendado pela Sociedade Brasileira de Arborização Urbana - SBAU.

A cobertura de vegetação presente nas AVs reflete a sua tipologia e função na paisagem. As AVs de caráter cultural (praças, largos e jardinetes) são as de maior número na paisagem, entretanto apresentam a menor proporção de área coberta por vegetação. 
A distribuição das AVs ao longo do município de Curitiba e de suas regionais é desigual em quantidade e irregular quanto à sua disposição, existindo uma concentração de $\mathrm{AVs}$ s prioritárias à conservação (parque e bosques) na região norte, de AVs culturais (praças, largos e jardinetes) na região central e há algumas tipologias que estão ausentes na região sul.

As regionais Bairro Novo e Pinheirinho são as que mais carecem de AVs, pois apresentam a menor quantidade, diversidade e cobertura de vegetação.

Os resultados apresentados podem contribuir para o planejamento de uso e ocupação do solo de Curitiba, uma vez que indicam as carências de AVs e a tipologia delas em relação às regionais administrativas da cidade.

\section{STATUS DA SUBMISSÃO}

Recebido: 20 dez., 2014

Aceito: 15 mar., 2016

\section{AUTOR(ES) PARA CORRESPONDÊNCIA}

\section{Mayssa Mascarenhas Grise}

Rua Ponta Grossa, 330, CEP 80610-170, Curitiba, PR, Brasil

e-mail: mayssamonteiro@gmail.com

\section{REFERÊNCIAS}

Biondi D, Althaus M. Árvores de Rua de Curitiba: cultivo manejo. Curitiba: FUPEF; 2005.

Biondi D. Floresta urbana: conceitos e terminologias. In: Biondi, D. Floresta urbana. Curitiba: O Autor; 2015.

Buccheri AT Fo. O planejamento dos espaços de uso público, livres de edificação e com vegetação (EUPLEVs) no município de Curitiba, PR: planejamento sistemático ou planejamento baseado em um modelo oportunista? [tese]. Curitiba: UFPR; 2010.

Caporusso D, Matias LF. Áreas verdes urbanas: avaliação e proposta conceitual. In: Anais do I Simpósio de PósGraduação em Geografia do Estado de São Paulo; 2008; Rio Claro. Rio Claro: UNESP; 2008. p. 71-87.

Cavalheiro F, Nucci JC, Guzzo P, Rocah YT. Proposição de terminologia para o verde urbano. Boletim Informativo da SBAU 1999; 7(3): 7.

Curitiba. Prefeitura Municipal. Lei $n^{\circ}$ 5.234. Diário Oficial do Município, Curitiba, PR (1975 dez. 10).
Curitiba. Prefeitura Municipal. Decreto $n^{\circ} 427$. Diário Oficial do Município, Curitiba, PR (1983 out. 20).

Curitiba. Prefeitura Municipal. Lei no 9.804. Diário Oficial do Município, Curitiba, PR (2000a jan. 3).

Curitiba. Prefeitura Municipal. Lei $n^{\circ}$ 9.806. Diário Oficial do Município, Curitiba, PR (2000b jan. 3).

Curitiba. Prefeitura Municipal. Lei $n^{\circ}$ 9.800. Diário Oficial do Município, Curitiba, PR (2000c jan. 3).

Curitiba. Secretaria Municipal de Meio Ambiente - SMMA. Plano Municipal de controle ambiental e desenvolvimento sustentável: diagnóstico versão III. Curitiba: SMMA; 2008.

Curitiba. Prefeitura Municipal. Prefeitura investe em arborização pública [online]. Curitiba: Prefeitura Municipal; 2014. [citado em 2014 jun. 1]. Disponível em: http://www.curitiba.pr.gov.br/noticias/prefeiturainveste-em-arborizacao-publica/28665

Heckmann KE, Manley PN, Schlesinger MD. Ecological integrity of remnant montane forests alongan urban gradient in the Sierra Nevada. Forest Ecology and Management 2008; 255(7): 2453-2466. http://dx.doi. org/10.1016/j.foreco.2008.01.005.

Instituto Brasileiro de Geografia e Estatística - IBGE. Censo 2010 [online]. Rio de Janeiro: IBGE; 2010. [citado em 2014 jun. 1]. Disponível em: http://censo2010.ibge. gov.br/resultados

Instituto de Pesquisa e Planejamento Urbano de Curitiba - IPPUC. Planilha de dados. Curitiba: IPPUC; 2014a.

Instituto de Pesquisa e Planejamento Urbano de Curitiba - IPPUC. Curitiba em dados [online]. Curitiba: IPPUC; 2014b. [citado em 2014 jun. 1]. Disponível em: http:// curitibaemdados.ippuc.org.br

Kozera C, Dittrich VAO, Silva AM. Composição florística da Floresta Ombrófila Mista Montana do Parque Municipal do Barigüi, Curitiba, PR. Floresta 2006 36(1): 45-57.

Lang S, Blaschke T. Análise da paisagem com SIG. São Paulo: Oficina dos Textos; 2009.

Loboda CR, De Angelis BLD. Áreas verdes públicas urbanas: conceitos, usos e funções. Ambiência 2005; 1(1): 125-139.

Matos E, Queiroz LP. Árvores para cidades. Salvador: MP do Estado da Bahia; 2009.

Milano MS, Dalcin EC. Arborização de vias públicas. Rio de Janeiro: Light; 2000.

Nucci JC. Qualidade ambiental e adensamento urbano: um estudo de ecologia e planejamento da paisagem aplicado ao distrito Santa Cecília. 2. ed. Curitiba: O Autor; 2008.

Puppi, I. C. Estruturação sanitária das cidades. 2. ed. São Paulo: CETESB/UFPR; 1981.

Vieira CHSD, Biondi DA. Dinâmica da cobertura vegetal na paisagem de Curitiba, PR. In: Terra CG, Andrade R. 
Interfaces entre tempo e espaço na construção da paisagem Sul-Americana. Rio de Janeiro: UFRJ; 2008. Coleção Paisagens Culturais v. 2.

Viezzer J, Biondi D, Martini A, Zamproni K. Tipologias das áreas verdes de Curitiba. In: Anais do IV Congresso
Florestal Paranaense [CD-ROM]; 2012; Curitiba. Curitiba: APRE; 2012.

Viezzer J. As linhas projetuais paisagísticas e a percepção dos usuários das praças de Curitiba - PR [dissertação]. Curitiba: UFPR; 2014. 